The $B D J$ News section accepts items that include general news, latest research and diary events that interest our

readers. Press releases or articles may be edited, and should include a colour photograph if possible. Please direct your correspondence to the News Editor, Arveen Bajaj at the BDJ, The Macmillan Building, 4 Crinan Street, London N1 9XW or by email to bdj@bda.org

\section{A step closer to mouth cancer drug availability}

Mouth cancer patients could soon have access to a new drug, currently not widely available on the NHS according to the Mouth Cancer Foundation. The organisation has been campaigning for the drug Cetuximab to become available to NHS patients.

The new cancer treatment has been available in Scotland since July 2006, but not England and Wales at present.

It is hoped that Cetuximab in combination with radiotherapy can be used as an alternative in mouth cancer patients for whom chemoradiotheraphy is inappropriate.

The charity successfully convinced the Appeal Panel of the National Institute for Health and Clinical Excellence (NICE) to ask its Appraisal Committee to reconsider its appraisal decision to ban the drug for head and neck cancer patients in England and Wales. The appraisal has now been returned to the Committee.

The Founder of the Mouth Cancer Foundation, Dr Vinod K Joshi, explained that the charity represented the views of its members constituting a wide population of patients with mouth cancer.

Currently both Carboplatin and Cisplatin are used for chemoradiotheraphy in the UK with Carboplatin side effects including suppressing the bone-marrow. Therefore, Cisplatin is the preferred treatment. The Appraisal Committee accepted that Cetuximab plus radiotherapy caused less severe adverse effects than either of the platinum-based chemoradiotherapy regimens.

\title{
Fluoride protection discussed in China conference
}

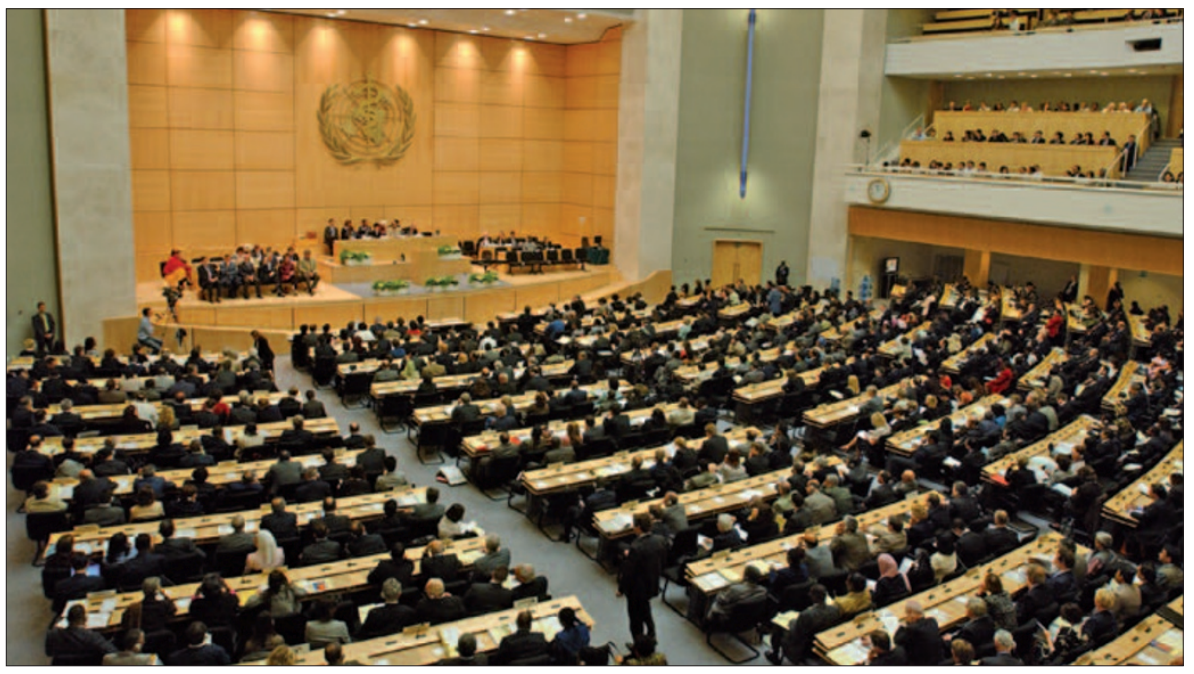

More than 70 experts in stomatology gathered at a conference on Oral Health through Fluoride for China and Southeast Asia, last month in Beijing, China. The conference was jointly organised by the World Health Organisation (WHO), the FDI World Dental Federation, the International Association for Dental Research (IADR) and the Chinese Stomalogical Association (CSA). The stomatological experts confirmed in a final conference declaration that fluoride toothpaste remains the most widespread and significant form of prevention of and protection against tooth decay used worldwide and is also the most rigorously evaluated vehicle for fluoride use.

Dr Lingzhi Kong, Vice Director of the Bureau of Disease Prevention and Control, Ministry of Health of the People's Republic of China, welcomed participants and said, 'Access to affordable fluoride is a human right for all citizens in China.

Professor Baez, representing the WHO Global Oral Health Programme in Geneva, explained that during the WHO's World Health Assembly in May, (pictured above) Member States adopted a resolution on oral health, which urged the establishment of national plans for the use of fluoride based on appropriate programmes for automatic administration through drinking water, salt or milk, or topical use, such as affordable toothpaste.

\section{0th reunion for dental class}

A group of dentists who graduated from Dundee Dental School recently returned to the city for a class reunion 50 years after they completed training. The returning class of 1957 came back to Dundee from around the globe, among them Professor Ivar Mjor, now of the University of Florida, and three Norwegian dentists who were among a large contingent of students from Norway in the 1950s.

Some of the Class of ' 57 are still working dentists and during their return they visited the facilities used to train today's students. They were met by current Dean, Professor Bill Saunders, and Dr Ann Shearer, President of Dundee and St Andrews Dental Alumni. 


\section{New Dean for Sheffield}

The University of Sheffield's School of Clinical Dentistry is under different leadership with the appointment of a new Dean. Professor Paul Speight began his post as Dean this month, succeeding Professor Trevor Walsh.

Professor Speight has worked at the University since 2003 when he was appointed as Professor and Head of Oral Pathology. His main research area is oral cancer and he has published over 170 original research papers, as well as a number of books and book chapters.
He is a past-president of the British Society for Oral and Maxillofacial Pathology and is the current President of the International Association of Oral Pathologists.

Professor Speight hopes to continue the work of Professor Trevor Walsh in improving and developing the School's facilities. Work is underway on the £5.5m extension to the School, which will provide new state-of the art research laboratories, as well as improving teaching facilities.

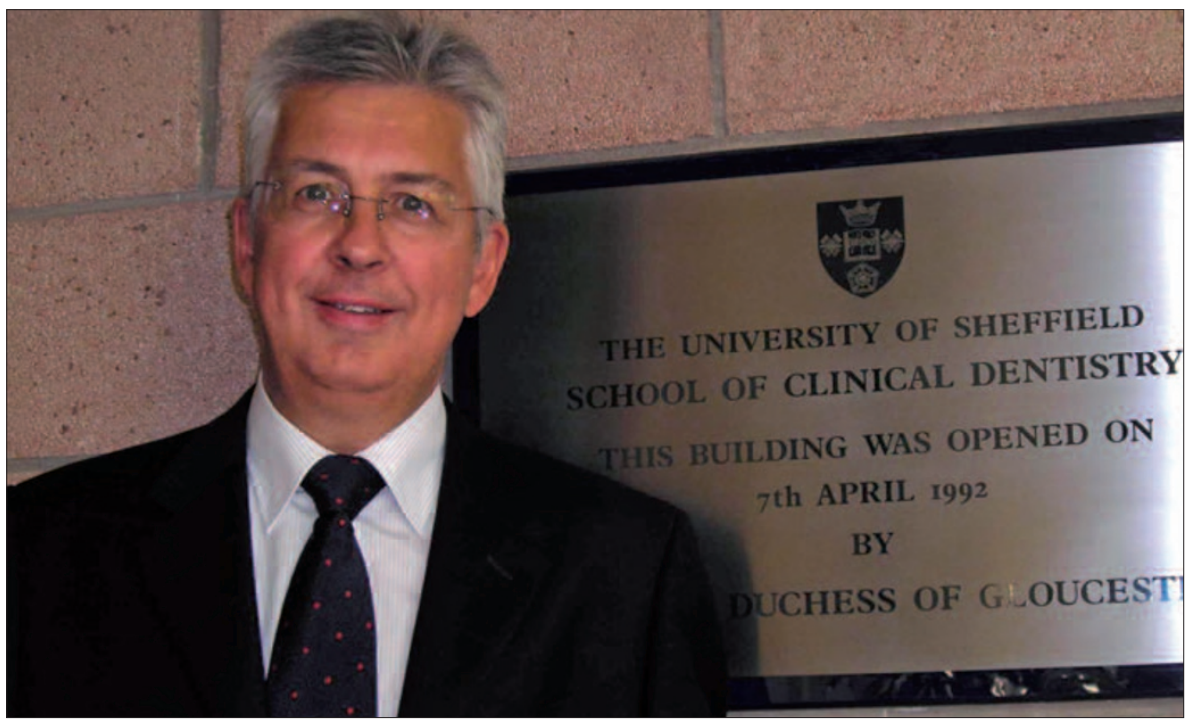

\section{GDC fees for 2008}

The GDC has set the 2008 fee levels for dental professionals. The first registration fee and annual retention fee (ARF) for dentists will be $£ 438$, an increase of $£ 18$ or $4.3 \%$ in line with inflation.

The annual retention fee for dental care professionals, which applies to dental hygienists, dental therapists and clinical dental technicians only at present, will be $£ 96$, an increase of $£ 24$ or $33 \%$. The first registration fee for all dental care professional groups will be $£ 96$.

The GDC claims its fee increases are needed to adequately resource the GDC's existing core functions, including registering the new groups of dental professionals such as dental nurses and dental technicians, as well as developing new initiatives to strengthen patient protection.

The GDC will also be introducing an ARF for the Specialist Lists for the first time in 2008. This is to cover the costs of maintaining the Lists and providing both a telephone and e-mail enquiry service for the many people looking for dental specialists. There will also be an application fee for dentists joining these lists.

\section{Resignation}

Trevor Mann has resigned as Chair of the Representative Body and from his other BDA posts citing personal reasons. The announcement was made at the meeting of the Representative Body on Saturday 13 October 2007. The Body agreed that Vice Chair Stuart Johnston will take on the Chair's duties until the Body next meets on 26 January 2008, when the election of a new Chair will take place.

\section{Tooth whitening investigation uncovers illegal treatments}

A new Which? magazine investigation has discovered that some beauty salons are cashing in on the trend for Hollywood-white teeth, and allowing unqualified staff to carry out treatments that could result in permanent damage if done incorrectly.

A Which? reporter posed as a potential client at six London beauty salons. All six said that their procedure was not performed by a dentist and half were using dangerous chemicals. The investigation also uncovered misleading advice and the use of whitening 'lasers' that have no proven effect.

The clinics were undercutting dentists' prices by employing beauty therapists who in some cases, after a few days' training, applied harmful chemicals that could damage clients' gums.

Most tooth whitening treatments use hydrogen peroxide or carbamide peroxide, but three salons offered a chlorine dioxide treatment and the other clinics use hydrogen peroxide in strengths from 0.6 to $10 \%$, which are above the legal limit.

Two of the clinics said that impressions of teeth would be taken, which is considered a procedure that should be carried out only by a dentist and therefore illegal if carried out by an untrained person.

Most of the clinics said that side effects could include white spots on gums or lips where the bleaching agent leaks from a shield. James Goolnik of the British Academy of Cosmetic Dentistry (BACD) who looked at the Which? research commented, 'These are chemical burns and there should not be any. Peroxide should be nowhere near the lip.' Half of the clinics visited advertised 'laser whitening' and one asked whether the reporter was allergic to lasers.

The General Dental Council (GDC) is now investigating 70 clinics found to be using unqualified staff and has asked Which? not to name them while enquiries continue. 


\section{UK's first new dental school for 40 years opens}

The Peninsula Dental School, the first new dental school in the UK for 40 years, opened its doors to its inaugural cohort of students last month. Around 188 people applied for the 64 places on the fouryear course and all 64 are educated to graduate level with many also achieving masters degrees and PhDs. A large percentage also has clinical experience from other healthcare disciplines.

The approval to establish a new dental school was won by the Peninsula Medical School in January 2006, when 64 of the 100 dental student places allocated by the Government were awarded to the South West and beyond. Under the leadership of Professor Liz Kay, Dean of the Peninsula Dental School, a non-traditional, community-based curriculum has been developed. Its objective is to create well-rounded, accomplished and professional dentists who will contribute to the dental health of the South West.

The degree is clinically intensive and makes use of community-based experience starting in Year 1 and building throughout the programme. There will be major emphasis on the sciences that underpin modern dental practice as well as the human and societal impact of dental disease. Students will have clinical experience under supervision in primary care settings at an early stage in their course, as early as six months into their first year. This is preceded by a period of clinical tuition in the school's state of the art 'phantom head room' based at the University of Plymouth. This uses the latest technology to simulate as closely as possible the clinical process with real patients.

The first cohort of students will undergo their first clinical experience

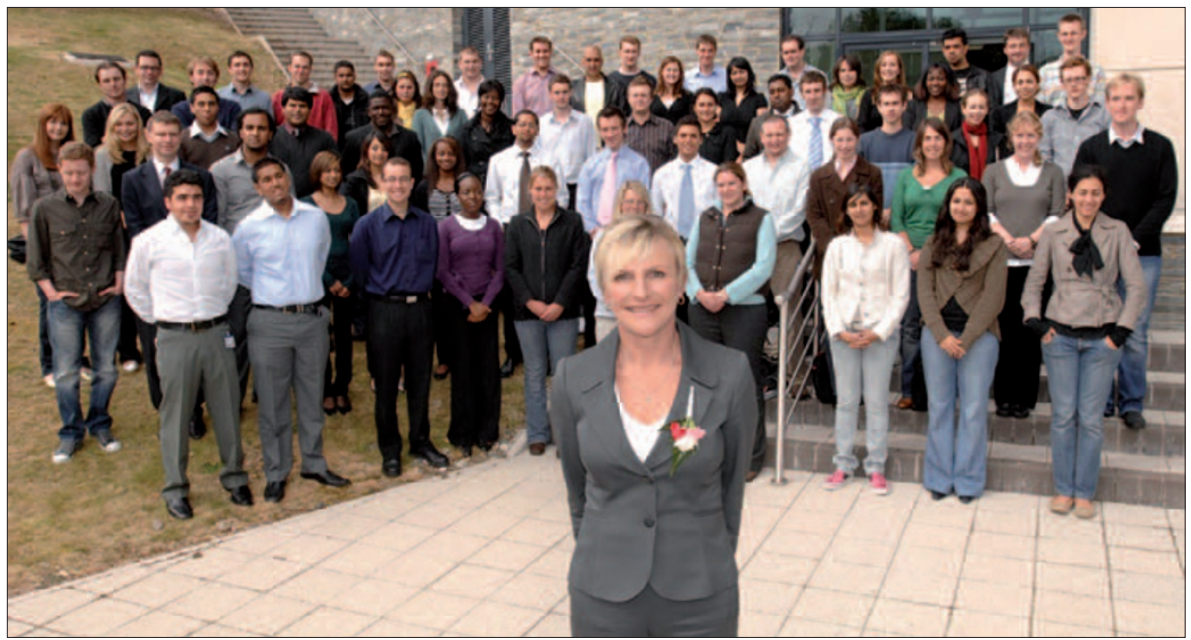

Professor Liz Kay, Dean of the Peninsula Dental School, with the first cohort of students

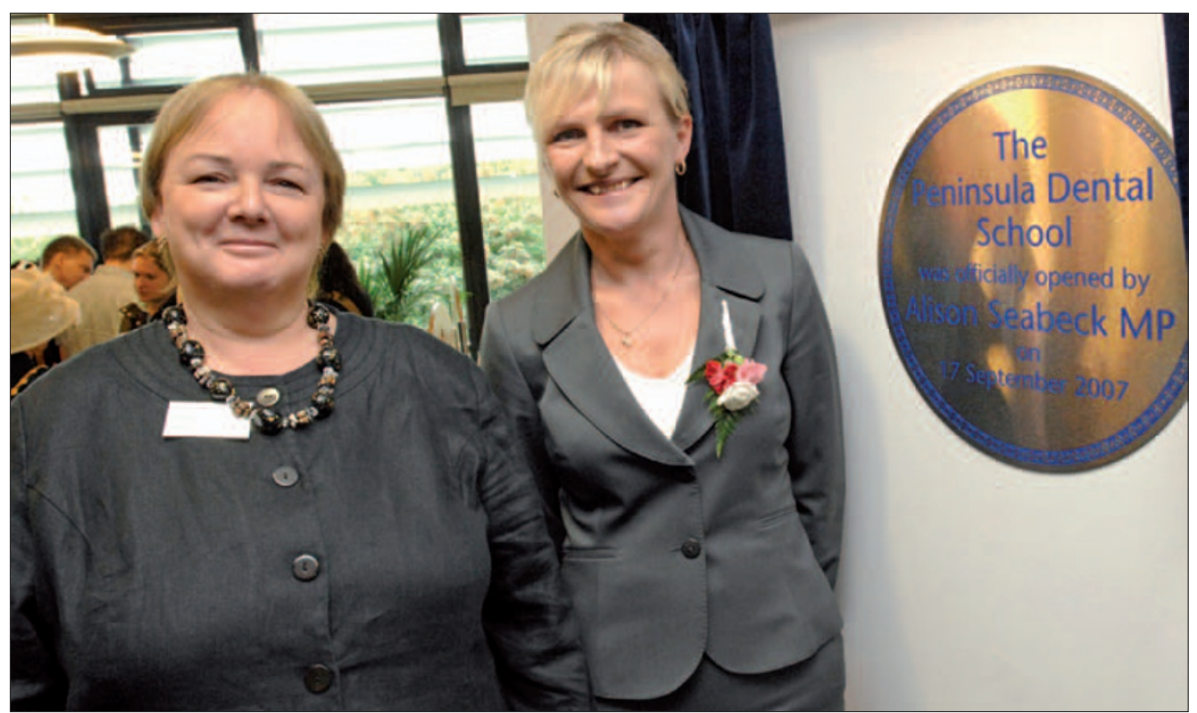

Susie Sanderson, Chair of the BDA Executive Board (left) with Professor Liz Kay, Dean in a primary care setting in Exeter in March 2008. While in this first stage of clinical experience they will carry out, under supervision, basic dental procedures which will become more involved as they develop throughout the four-year course. It is hoped that by training students in an NHS primary care environment, and instilling in them a sense of community responsibility, more will be encouraged to practise in the NHS when they graduate.

The first cohort of students will begin their training in Plymouth on the University of Plymouth campus while purpose-built facilities are developed in Devonport, Exeter and Truro.

It is believed that the impact made by Peninsula Dental School students will be soon in coming - it is expected that they will carry out basic treatments and tests under supervision for local NHS patients in the second half of their first year. At its peak it is estimated that the Peninsula Dental School across the South West will treat 512 patients a day.

Like the Peninsula Medical School, the Peninsula Dental School will also become a national and international centre for dental research. It has established a strategy for research and is building relationships with other dental schools and centres of dental research in the UK and overseas. Some research has already been undertaken by academic staff, including the Shirley Glasstone Hughes Memorial Prize for Dental Research.

The Peninsula Dental School was established as a partnership between the Universities of Exeter and Plymouth and the NHS in Devon and Cornwall in January 2006. It was formed, following a successful bid to the Government, as part of a national expansion of dental student numbers in the UK.

They include students like Caroline Muskett, 37, a fully trained nurse from Newton Abbot. She has a degree in biochemistry and has a DipHE in Nursing. She said, 'I have a good science degree and, from my nursing career, experience of the clinical side, so when I heard about the Peninsula Dental School I thought it would be a great opportunity for me.'

Another new student, Jeremy Lenaerts, 28, lives in Exeter and has a degree in microbiology and a $\mathrm{PhD}$ in biological sciences. He achieved his $\mathrm{PhD}$ at the University of Exeter while at the same time working as a research assistant, and he has recently been working for a company that specialises in the development of medical research instruments. 


\section{Spicy painkilling alternative}

A new anaesthetic method that kills pain without producing numbness or preventing movement has been developed. A key ingredient in chilli peppers, when used with a local anaesthetic, could be used for ending pain in the dentist's chair and on the operating table without the potentially dangerous side effects and numbness of traditional anaesthesia, according to a new Harvard Medical School study.

Researchers reporting in Nature found that a combination of capsaicin, the active ingredient in chilli peppers and QX-314, a derivative of lidocaine, effectively silences pain-sensing nerve cells without disturbing other neurons that control motor function and other sensations. The two compounds homed in on pain-sensing nerves in a specific area, leaving other functions unaffected.

It could be used for situations where patients require anaesthetic, but also need to be able to move or control muscles, such as in childbirth and in some dental procedures.

Dr Bruce Bean of Harvard Medical School in Boston, Massachusetts, USA and his colleagues targeted the pain by taking advantage of an ion channel called TRPV1, which is only present in pain-sensing nerve cells. This channel opens when it senses capsaicin. Working on cultures of neurons, the researchers used capsaicin to open the ion channel, allowing QX-314 to enter the cell. QX-314 is similar to the commonly-used local anaesthetic lidocaine, but, unlike lidocaine, it has no effect unless it is acting

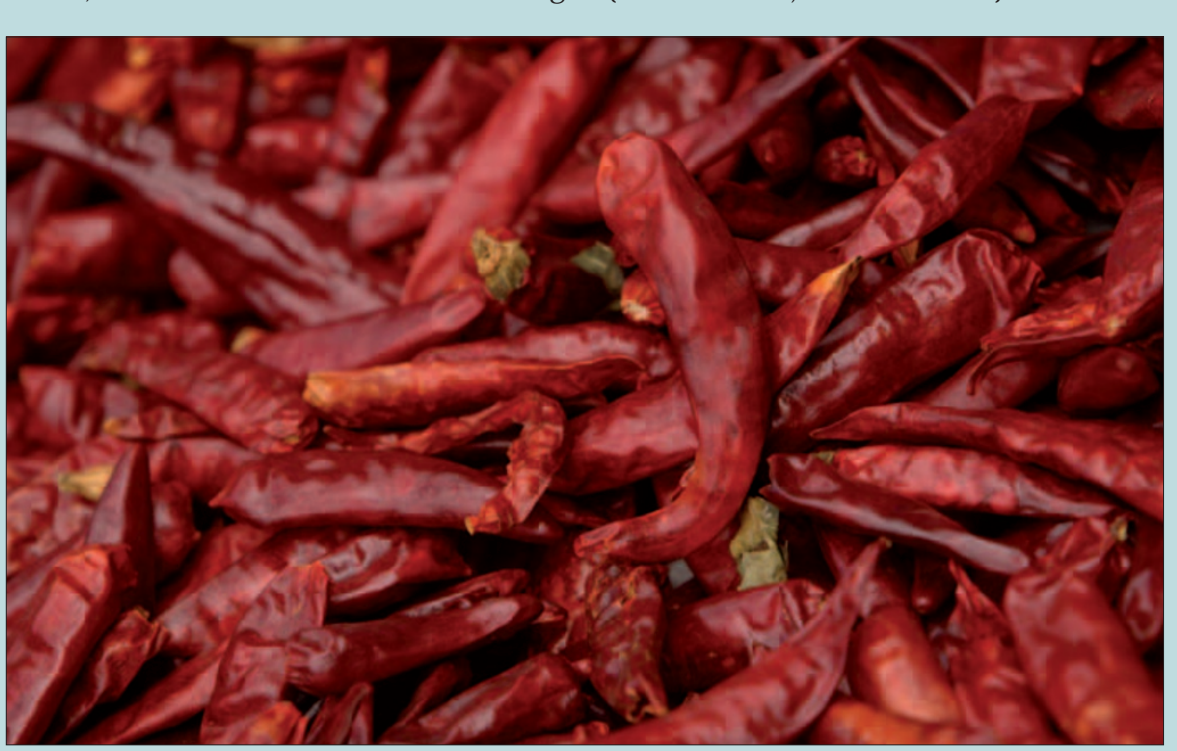
rons, where it could then dampen the action of these cells.

The combination of compounds also worked in live animals. When the team injected rats with QX-314 and capsaicin, the animals did not react to a normallypainful stimulus applied to their foot once the painkiller had taken effect. But the rats could move around as normal. (Nature 2007; 449: 607-610).

\section{Cash injection for decontamination}

Dentists in Scotland are to receive an extra $£ 5$ million to help them meet new decontamination requirements. New guidelines mean that from December 2009, dental practices must ensure that all decontamination and cleaning of instruments is done in a separate, designated area of the practice. The extra funding is in recognition of the additional costs these new measures will incur for dentists. A dental premises

from within a cell. The team found that capsaicin did indeed allow the anaesthetic to only enter pain-sensing neu-

strategy is also to be drawn up to identify what steps need to be taken to make sure dental practices have got long term plans to meet the new requirements. Making the announcement at NHS Education Scotland's annual dental conference in Dunkeld, Minister for Public Health Shona Robison said, 'I am conscious of the additional demands that will be placed on dental practices by these new decontamination guidelines. That is why
I am making available immediately £5 million of capital funding through NHS boards so that practitioners are able to make early preparations to ensure that appropriate measures are put in place.' Scotland's Chief Dental Officer, Margie Taylor, is to take forward the development of a dental premises strategy which will identify comprehensively what needs to be done to upgrade current dental practices and what steps need to be taken where internal improvements may not be possible. 


\section{Dental work can boost self-esteem}

Dental work to improve an individual's smile could boost self-confidence, a survey has found. An Ipsos-MORI survey has found that as many as 19 million people feel their self-confidence could be boosted by dental work to improve their smile.

Nearly one in three adults (30\%) said having attractive teeth would help overcome embarrassment about personal appearance and $46 \%$ believed an attractive smile could improve their appearance.

The survey was commissioned by orthodontist Dr Andrew McCance, who has invested half a million pounds in research at University College London to create a three-dimensional surgical technique to aid surgeons treating facial abnormality.

Commenting on the survey, Dr McCance said, 'Anxiety about their appearance means people quite literally cannot grin and bear it. Their embarrassment with their facial appearance has hampered their careers or stopped them forming relationships. To put it at its simplest, they've been too embarrassed by crooked teeth or misshapen jaws to risk a smile and people should not live like that.'

The survey which comprised a nationally-representative sample of people aged over 15 years of age throughout Great Britain, found that 1.25 million adults feel generally less attractive because they have not had corrective orthodontic treatment. The same number say their unattractive smile has prevented them from laughing and smiling as much as they would like. Almost a million adults believe their unattractive smile has lowered their self-esteem and a similar number say it causes them difficulty in meeting people face-to-face.

\section{Snake venom used in oral surgery for faster healing}

A new adhesive derived from snake venom has been found to be useful in postoperative healing times for oral surgery procedures, according to a study. It found that an adhesive made from an enzyme found in snake venom was a more effective and beneficial adhesive when used to close surgical incisions than traditional sutures.

The study followed 15 patients during the healing process after a gingival graft. When the adhesive derived from snake venom was used, those patients had faster recovery and bet- ter results than those treated with traditional sutures.

Study author Monica Barbosa of Bauru Dental School at the University of Sao Paulo, Brazil, claimed that the adhesive may stimulate faster tissue repair as it is a more natural form of adhesive in comparison to traditional sutures used after surgery, but that more studies were needed to fully evaluate its effectiveness.

The paper Fibrin adhesive derived from snake venom in periodontal surgery is published in the Journal of Periodontology, 2007; 78: 2026-2031.

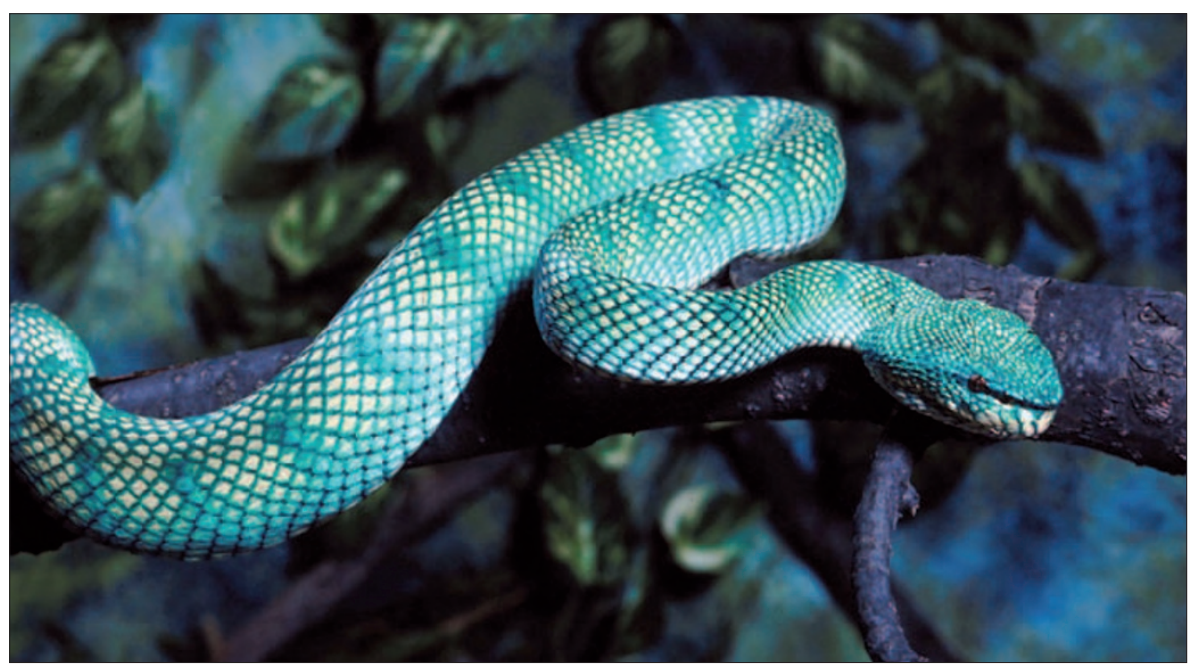

November

University of Victoria's Annual Current Concepts in Dentistry Date: 10-13 November 2007 Venue: Victoria, British Columbia, Canada Tel: +1 (250) 721-4747

Email: register@uvcs.uvic.ca www.continuingstudies.uvic.ca/dental

East Lancashire \&t East Cheshire BDA Branch Dinner/Dance Date: 10 November 2007

Venue: Victoria \& Albert Marriott Hotel, Water Street, Manchester

Tel: 07815088816

Email: derbylm@hotmail.com

BACD Fourth Annual Conference

Date: 15-17 November 2007

Venue: Novotel London West, Hammersmith, London Email:suzy@bacd.com www.bacd.com

2nd International Conference on Evidence-based Advanced Dentistry and Silver Jubilee Celebrations of the Faculty of Dentistry, The University of Hong Kong Date: 16-19 Nov 2007

Venue: Hong Kong Academy of Medicine Email:dent25cb@hku.hk

www.dent25.hku.hk

The Dental Pan-Society

Conference 2007

Date: 16-17 November 2007

Venue: International Convention Centre,

Birmingham

Tel: 01494581526

Email admin@pandental2007.org

www.pandental2007.org

Portuguese Dental Association Annual Meeting

Date: 22-24 November 2007

Venue: Lisbon Conference Centre,

Portugal

Email ordem@omd.pt

www.omd.pt

December

Seventh Annual Premier Symposium Date: Saturday 1 December 2007

Venue: Kings College,

London Waterloo campus

Email: sarah.cunliffe@mps.org.uk

www.dentalprotection.org 